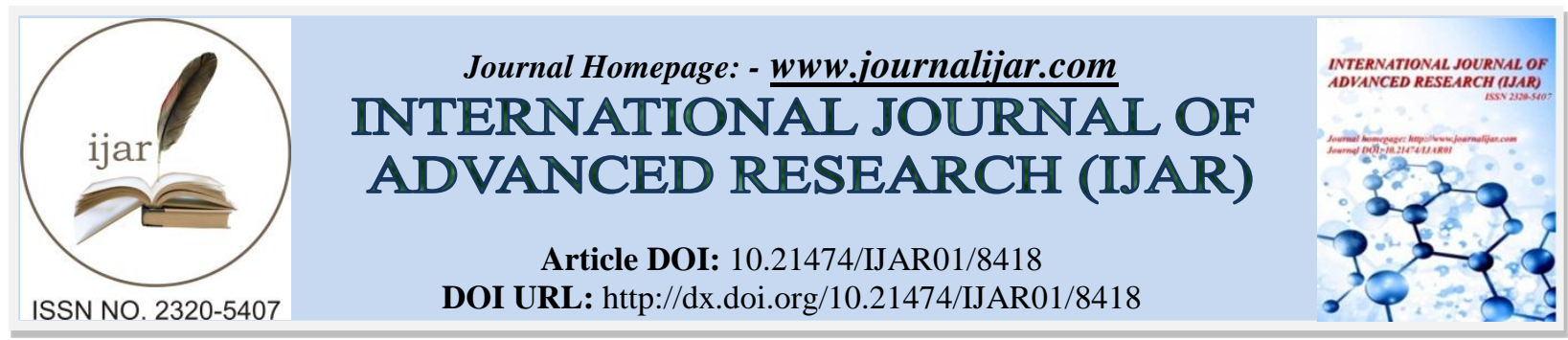

RESEARCH ARTICLE

\title{
IMPACT OF IT MANAGER'S HUMAN CAPITAL DEVELOPMENT ON BIM INNOVATION IN SME FIRMS.
}

Sa'id Kori ${ }^{1}$ and Hauwa Olabisi Yusuf ${ }^{2}$.

1. Department of Architecture University of Liverpool, Liverpool, UK.

2. Department of Architecture Baze University, Abuja, Nigeria.

\section{Manuscript Info}

Manuscript History

Received: 16 November 2018

Final Accepted: 18 December 2018

Published: January 2019

\section{Key words:-}

Building information modelling (BIM), Architecture engineering and construction (AEC), Small and medium enterprises (SME), BIM business value creation (BBVC), Human capital development.

\begin{abstract}
The Architecture, Engineering and Construction (AEC) industry is facing a paradigm shift in the adoption of Building Information Modelling (BIM). However, the shift to its adoption and implementation in the emerging markets has brought distortion in both the business processes and environment for Small and Medium Enterprises (SME architectural) in the industry. This is attributed to the lack of clear orientation in Human Capital Development of the firms. This paper identifies the different strategies concerning the development of the IT managers human capital; development. This is achieved by identifying how BIM adopters differ from non-adopters in the ways their IT manager's Human capital development is considered. The study involves twostep analysis; empirical enquiry to identify the various indicators of the IT manager's human capital development and the analysis of its impact on BIM adoption. The empirical enquiry comprised of research framework and fieldwork data collection. The framework was used to collect data from the fieldwork. It involved a questionnaire survey with a sample of SME architectural firms in Nigeria. The survey involved administering questionnaires by hand to 351 firms within nine cities in Nigeria during September 2015. It yielded 228 completed questionnaires by the end of December 2015. Using regression analysis, the result indicates that, there are four critical indicators that determine the role of IT manager in BIM innovation, these are; the educational attainment, nature of employment, previous IT experience and job satisfaction.
\end{abstract}

Copy Right, IJAR, 2018. All rights reserved.

\section{Introduction:-}

IT Managers play a decisive role as change facilitators in the BIM adoption process (Holzer, 2015) and their motivation and capability can be crucial for innovation in SME architectural firms (Lu \& Sexton, 2009). Hence, as change facilitators, IT managers assist key stakeholders within an SME architectural firm by mentoring them on their path to deal with change. Holzer (2015) emphasised the relevance of the IT manager in driving BIM innovation stressing that they need to base their work on a strong awareness of the situations they encounter within their organisation and beyond. They are the ones who understand the broader industry context when it comes to technology uptake and its reconciliation with existing practices. They empower them to engage with a changing context that affects their professional and personal life. Hence, the IT manager in this context can be defined as the staff responsible for leading technology innovation in the firm. For the BIM adopter, this could be the BIM manager, while for non-adopters, this can be any individual who champions, or is responsible for, leading IT activities in the firm. 
This paper aims to identify the various predictors of motivation and capability of IT managers in the BIM Business value creation. The study starts by identifying how BIM adopters differ from non-adopters in the role of their IT manager toward Human capital development. Using an extensive review of literature, the paper starts by identifying four indicators from literature to form the variables or predictors in determining the motivation and capability of the IT manager in an SME architectural firm, and these are; the nature of employment, higher education qualifications, experience, and job satisfaction.

With regard to the nature of employment, Malhotra, Smets, \& Morris, (2016) suggested that the creation of new roles and career paths in order to allow for flexible working and better work-life balance does not only accommodate staff needs, but can help make businesses more innovative. They argue that, while SME architectural firms find it challenging to change working practices in response to staff demands for flexibility, the study, which involved law firms in London, shows that taking a proactive, creative approach to work-life balance and careerpathing can benefit a firm's longer-term competitiveness. In doing so, the firm not only helps to retain the valuable talents of their employees to exploit innovation but, by organising it in new ways, their ability to deliver the innovations that their client seeks is enhanced (Malhotra et al., 2016). This applies, in particular, to the BIM adoption process where innovation is driven more by people and knowledge than the technology infrastructure. Their study confirms the relationship between the nature of the change facilitator's employment and the motivation and capability of the firm to innovate. Innovation in a knowledge-intensive firm emerges from practice, through people with various kinds of knowledge and experience coming together to address the new and different challenges presented by their clients (Malhotra et al., 2016). However, this proves difficult under the traditional design process of AEC firms where the firm hierarchy is required to make compromises between the time spent mentoring and the sharing of specialised knowledge. For example, this involves standing back and looking at existing processes in different ways, building relations with clients, winning new and attractive jobs, and achieving stringent targets for billable hours. Malhotra et al. (2016) argued that firms can alleviate these compromises and smooth the path to both operational and technical innovation, which can help to generate new, cutting edge solutions and to roll them out with greater efficiency and at a lower cost. Hence, the nature of the employment of the IT manager may also be a predictor of the BIM adoption success.

With regard to educational attainment and experience, Baldwin and Johnson (1996) argued that the most innovative firms offer more formal and informal continuous training and have more innovative human resource policies, implicitly recognising the relevance of HC to their performance. Yang and Lin (2009) and Morris and Snell (2011) emphasised that the experience of the individual employee responsible for innovative activities is the most crucial part of $\mathrm{HC}$ development in terms of enhancing innovation in a firm. In fact, the knowledge specificity and the speed of change associated with innovation demands permanent growth in the competency levels of employees, requiring high degrees of motivation and their participation in the decision process. Becker (1994) examined the consequences of investing in a person's knowledge and skills through education and training. Educational attainment and experience form the competency of a manager (Baldwin \& Johnson, 1996) and they are a major factor in innovation success (McGuirk, Lenihan, \& Hart, 2015). This assertion has also been confirmed by Hayton (2005) who added that cognitive resources, along with experience and values, were found to have a significant influence on the way managers comprehend and interpret organisational stimuli, and thus on their problem-solving capabilities. Considering their influence through their decision power in the innovation processes, the existence of these HC indicators for the IT manager's competence may be crucial to the innovation capabilities and motivation of the firm and may, in turn, influence the BIM adoption process. The competence of the IT manager, who is responsible for guiding the implementation process of innovation, can be measured by the level of educational attainment and experience; a study by Toner (2011) has shown that there is a strong relationship between higher levels of education and technical training and an increased demand for the supply of technical and organisational innovation. For example, Romer (1990) measured HC by assessing the cumulative effects of formal education and on-the-job training. While the latter can be limiting, it is easily measured; hence, the technical, or on-job, training can also be defined as the education attainment of the IT manager. The OECD report (OECD, 2011) suggests an array of skills required for innovation, including basic and digital literacy, and academic and technical skills; however, education and technical skills remain an essential prerequisite to innovation.

Furthermore, with regard to job satisfaction, Binder and Coad (2013) suggested that work is an important part of human life and has a strong effect on a person's happiness or satisfaction. Job satisfaction is widely studied in the context of organisational behaviour (Zhou \& George, 2001). Moreover, in a study on the effect of aggregate job satisfaction and organisational innovation in firms, job satisfaction was found to be a significant predictor of 
innovation, suggesting that employees who experience job satisfaction will support rather than resist innovation (Shipton, Fay, West, Patterson, and Birdi (2005). However, in another context, a study on creativity in organisations examined the conditions in which employee job dissatisfaction might lead to creativity (Zhou and George (2001). This study involved 149 office employees from a manufacturing firm and found that those who were dissatisfied with their jobs but committed to remaining in their position found that they made improvements in their workplace that resulted in increased creativity.

From the above discussion, the study formulated the following hypotheses for empirical study which is also illustrated in Figure 7:

H1: The motivation and capabilities of the IT manager toward innovation in SME architectural firms has a significant relationship with BBVC.

H0: The motivation and capabilities of IT manager toward innovation in SME architectural firms has no significant correlation with BBVC.

\section{Sub-Hypotheses:}

Ha: Firms that develop their HC innovation from IT managers with a flexible work life are likely to succeed in BBVC.

$\mathrm{Hb}$ : Firms that develop their HC innovation from IT managers with higher education qualifications are likely to succeed in BBVC.

Hc: Firms that develop their HC innovation from IT managers with previous IT experience are likely to succeed in BBVC.

Hd: Firms that develop their HC innovation from IT managers with higher job satisfaction are likely to succeed in BBVC.

\section{Research framework}

Measure of bim success in the sme architectural firms.

This section discusses the dependent variable of the study, which is BBVC. It starts by defining BIM from the business perspective, and the emergence of the term 'business value' in BIM. Subsequently, the study defines the term BBVC through the literature of IT business value and built its case from that field.

Vass (2015) suggested that most studies on measuring business value in the field focus on evaluating the value of IT. Others concentrate on determining suitable metrics or key performance indicators to measure and evaluate the effects of implementing IT, and in particular to measure any increased productivity from IT. This is also true in the case of current construction management and BIM research (Aranda-Mena, Crawford, Chevez, \& Froese, 2009; Barlish \& Sullivan, 2012; McGraw Hill Construction, 2014; Vass, 2014). For example, Curley (2004) explicitly states that, in order to measure the business value of IT in a firm, a maturity and capability metric is essential. This is also reiterated by Succar (2009) and Aranda-Mena et al. (2009) who argued that generating business value through BIM is highly dependent on the individual capabilities of firms. Similarly, McGraw-Hill (2009) suggested that numerous successful firms invest to make sure clients are aware of their BIM capabilities in order to create business value. All the above assertions point to the level of maturity and capability as essential in generating IT business value. (Curley, 2004; Kohli \& Grover, 2008; Racheva, Daneva, \& Sikkel, 2009).

\section{Bim Maturity And Capability Model}

Measurement of BIM success or maturity models in firms has well been established in the literature; it was early started by the National BIM Standard Capability Maturity Model (NBIMS-CMM), developed in the U.S. by the National Institute of Building Sciences (NIBS, 2007). NBIMS-CMM consists of eleven critical BIM measures, including business process, delivery method, data richness and information accuracy. It focuses only on information management and has been therefore criticised for not reflecting the diverse facets of BIM. Critics have also questioned its usefulness and usability due to its structural limitations (Succar, 2010). So profound and powerful these critics were and resulted in the introduction of new models that tried to build on NBIM-CMM and provide more optimised models. However, following the success of the UK BIM Task Group over the past years in defining and implementing BIM Level 2 within Government Departments. The emergence of new models seeks better ways of measuring BIM. Frameworks such as the BIM Maturity Matrix (Succar, 2010), the Virtual Design and Construction (VDC) Scorecard (Kam, 2015) and the BIM Maturity Measure (BIMMM) (Ammar et. al, 2017), have been designed to improve previous models. They have supplemented past measures with diverse areas of measurement that represent much broader dimensions of BIM e.g. policies, technologies and processes. Individually and collectively, coexisting AMs have contributed to the growing body of literature that examines BIM use. 
In order to develop the measure for BBVC based on these various models and efforts, it is important to reflect on all the existing maturity models/indices of maturity and capability concerning the BIM process.

Numerous models contribute to the development of viable BIM maturity and capability models. Among them are; Control Objects for Information and Related Technology, CMMI (Capability Maturity Model Integration), CSCMM (Construction Supply Chain Maturity Model), I-CMM (Interactive Capability Maturity Model), Knowledge Retention Maturity Levels, LESAT (Lean Enterprise Self-Assessment Tool), P3M3 (Portfolio, Programme and Project Management Maturity Model), PCMM (People Capability Maturity Model), (PM) ${ }^{2}$ (Project Management Process Maturity Model), SPICE (Standardised Process Improvement for Construction Enterprises), Supply Chain Management Process Maturity Model, and BPO (Business Process Orientation Maturity Model). These models as listed in (Succar, Sher, \& Williams, 2012) were studied by Kori and Kiviniemi (2015) with regard to BIM in Nigeria, and the outcome was that most of these models were broad in approach and could collectively form a basis for a range of BIM capabilities. However, Succar (2009) suggested there is not enough differentiation between the notion of capability and that of maturity. Hence Succar (2009) defines 'BIM maturity' as, "the quality, repeatability and degree of excellence within a BIM capability and developed the BIM Maturity Matrix". Succar described BIM capabilities in three stages:

1. Object-based modelling;

2. Model-based collaboration; and

3. Network-based integration.

Barlish and Sullivan (2012) highlighted that it is the extent of an organisation's performance or ability within a particular stage that is measured to determine their BIM maturity. This is gauged according to the five maturity levels shown in Figure 1: BIM maturity levels at different stages

The BIM maturity level at Stage 1, for example, indicated an organisation performing testing or pilot projects to determine the benefits of BIM (Barlish \& Sullivan, 2012); this is the first stage (object-based modelling) and within that phase they are at an 'ad-hoc' or 'defined' maturity level, working for more optimisation through increasing testing. Furthermore, the organisation's level of BIM maturity can be accessed via general objectives within a level similar to Figure 1: BIM maturity levels at different stages

Figure 12: The BIM Maturity Map by Bew and Richards (2008) in BIM Overlay to the RIBA Outline Plan of Work (Sinclair, 2012), or matrix of competencies, is similar to Building SMART Alliance's BIM Capability Maturity Model. Organisations' varying levels of maturity should be taken into consideration when comparing organisations' BIM business cases.

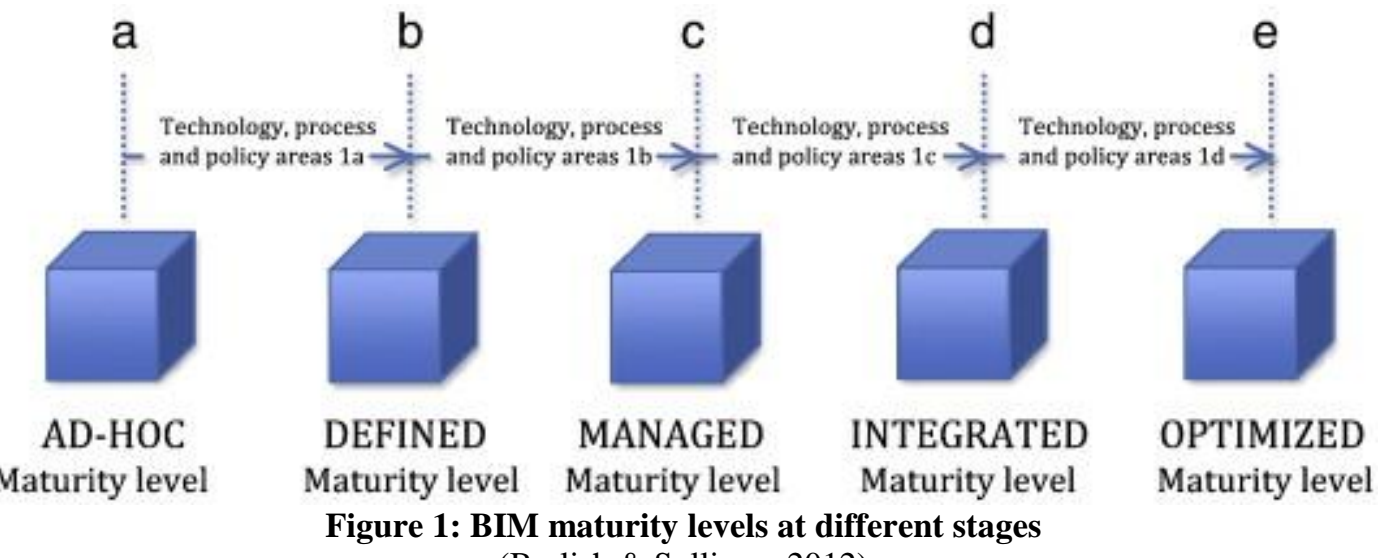

(Barlish \& Sullivan, 2012) 


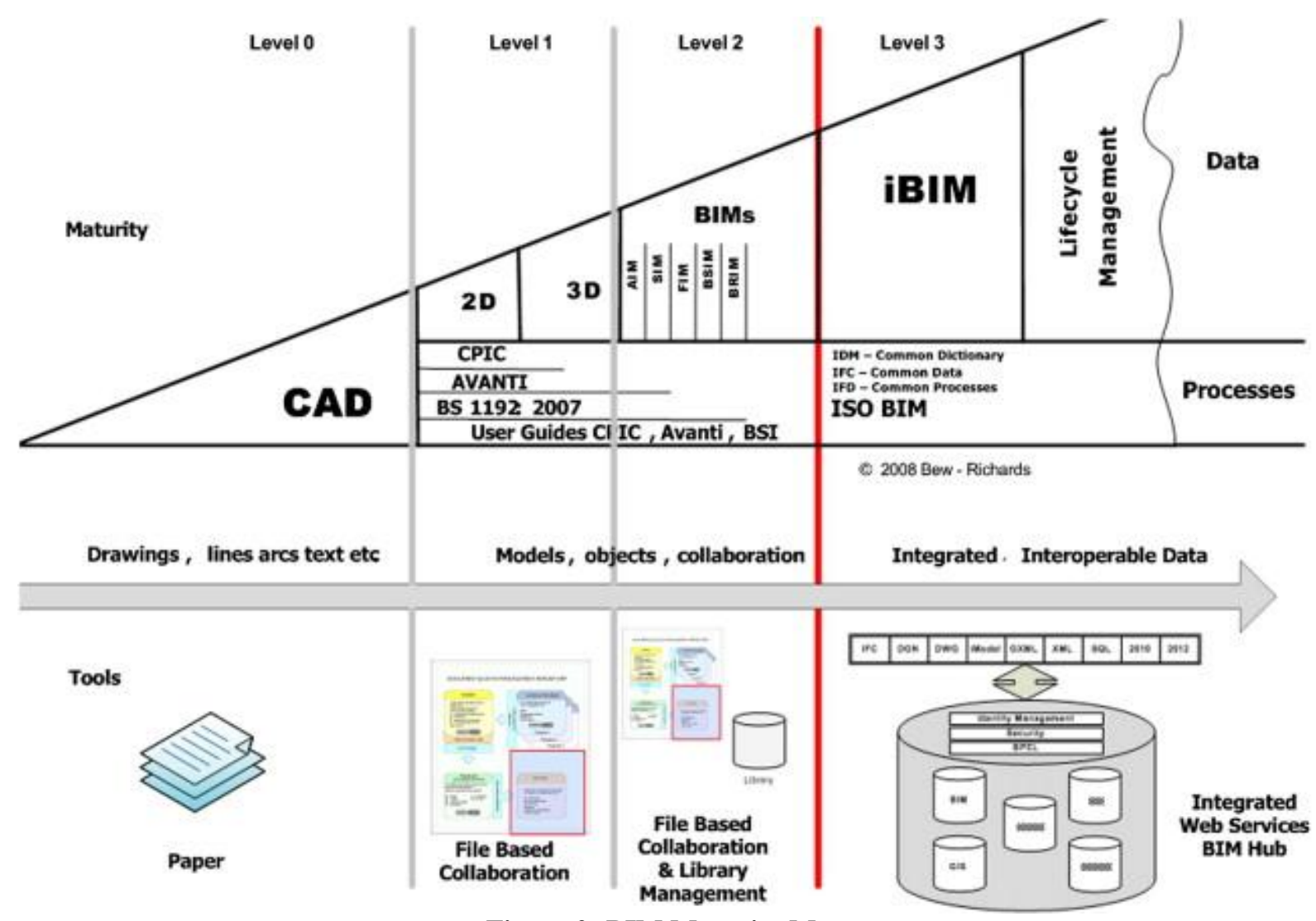

Figure 2: BIM Maturity Map

(Bew \& Richards, 2008)

Consequently, in accordance with the BIM Maturity map by Bew and Richards (2008) having identified the BIM fields, Succar (2009) further developed five stages which delineate capability milestones. Succar (2009) describes BIM capability as the basic ability to perform a task, deliver a service, or generate a product. BIM capability stages (or BIM stages) define the major milestones for achievement by teams and organisations as they adopt BIM technologies and concepts. BIM stages identify a fixed starting point (the status before BIM implementation), three fixed BIM stages, and a variable ending point, which allows for unforeseen future advancements in technology. The following is a list and description of each of the five stages developed in accordance with Succar and Kassem (2015) BIM Maturity Matrix, which is subsequently used as the baseline in developing the measure of BBVC for this study.

\section{Pre-BIM status:}

Disjointed Project Delivery : The construction industry is characterised by adversarial relationships where contractual arrangements encourage risk-avoidance and risk-shedding. Much dependence is placed on 2D documentation to describe a 3D reality. Even when some 3D visualisations are generated, these are often disjointed and reliant on twodimensional documentation and detailing. Quantities, cost estimates and specifications are neither derived from the visualisation model nor linked to documentation. Similarly, collaborative practices between stakeholders are not prioritised and workflow is linear and asynchronous. Under pre-BIM conditions, the industry suffers from low investment in technology and a lack of interoperability.

BIM Stage 1 Object-Based Modelling :

Collaborative practices at Stage 1 are similar to the pre-BIM status and there are no significant model-based interchanges between different disciplines. Data exchanges between project stakeholders are uni-directional and communications continue to be asynchronous and disjointed. As only minor process changes occur at Stage 1, preBIM contractual relations, risk allocations and organisational behaviour persist. However, the semantic nature of object-based models and their 'hunger' for early and detailed resolutions of design and construction challenges encourage the 'fast-tracking of project lifecycle phases - when a project is still executed in a phased manner yet design and construction activities are overlapped to save time. 


\section{BIM Stage 2:}

Model-Based Collaboration : Although communication between BIM players continue to be asynchronous, pre-BIM demarcation lines separating roles, disciplines and lifecycle phases start to fade. Some contractual amendments become necessary as model-based interchanges augment and start replacing document-based workflows. Stage 2 also alters the granularity of modelling performed at each lifecycle phase as higher-detail construction models move forward and replace (partially or fully) lower-detail design models.

\section{BIM Stage 3:}

Network-Based Integration : At this capability stage, semantically-rich integrated models are created, shared and maintained collaboratively across project lifecycle phases. This integration can be achieved through 'model server' technologies (using proprietary, open or non-proprietary formats), single-integrated/distributed-federated databases, Cloud Computing or SaaS (Software as a Service). BIM Stage 3 models become interdisciplinary nD models allowing complex analyses at early stages of virtual design and construction. At this stage, model deliverables extend beyond semantic object properties to include business intelligence, lean construction principles, green policies and whole lifecycle costing. Collaborative work now 'spirals iteratively' around an extensive, unified and shareable data model. From a process perspective, a synchronous interchange of the model and document-based data cause project lifecycle phases to overlap extensively forming a phase-less process.

\section{Integrated Project Delivery:}

Interdependent, Real-Time Models : This is the most suitable stage representing a long-term vision of BIM as an amalgamation of domain technologies, processes and policies. The term is generic enough and potentially more readily understandable by industry than 'Fully Integrated and Automated Technology', Integrated Design Solutions, or ' $\mathrm{nD}$ Modelling, as three prominent examples. The selection of Integrated Project Delivery (IPD) as the goal of BIM implementation is not to the exclusion of other visions appearing under different names. On the contrary, the path from Pre-BIM (a fixed starting point), passing through three well-defined stages towards a loosely defined IPD is an attempt to include all pertinent BIM visions irrespective of their originating sources.

Similarly, Aranda-Mena et al. (2009) developed a model based on the Val IT approach (ITGI, 2006) identified three layers of capability:

1. Technical capability: the specific technological capabilities delivered by the programme.

2. Operational capability: the operational capabilities that are supported by the technological capabilities.

3. Business capability: the overall business capabilities enabled by the operational capabilities.

The discussion above provided a baseline for shaping an appropriate model that could fit the context of this study. However, because the study deals with SME architectural firms in a Nigerian context, there may be some layers and elements that might need to be re-evaluated and contextualised. Hence, the following discussion will focus on the contextualisation of the model.

\section{Methodology:-}

The study involves two-step analysis; empirical enquiry to identify the various indicators of the IT manager's human capital development and the analysis of its impact on BIM adoption. The empirical enquiry comprised of research framework and fieldwork data collection. The framework comprises of two main variables, these are; The independent variables which involved the IT manager's indicators and the dependent variables which is the measure of BIM Business Value, the framework was used to collect data from the fieldwork. It involved a questionnaire survey with a sample of SME architectural firms in Nigeria. The survey involved administering questionnaires by hand to 351 firms within nine cities in Nigeria during September 2015. It yielded 228 completed questionnaires by the end of December 2015. The survey data enable the assessment of the framework using multiple regression analysis. The regression analysis was done based on two-step analysis; first through investigating the correlation between the main variables of the IT manager component and the BIM Business value creation which is a combination of the four indicators, secondly, the effects of each of the four indicators on the BIM business Value creation. The outcome provides with the Relative Weighting Value (RWV) of each of the four indicators on the BIM Business Value Creation in the SME firms.

\section{Analysis:-}

This section discusses the data analysis and results of the study. In order to investigate the relationship in the first step of the analysis, a multiple linear regression and correlation analysis was conducted to assess whether the 
independent variables predict the dependent variable (criterion). The multiple linear regression assesses the relationship between a set of dichotomies, or ordinal, or interval/ratio predictor variables on an interval/ratio criterion variable (Solutions, 2013). Hence, the following regression equation (main effects model) was used for each component as a regression model:

$\mathbf{y}=\mathbf{b}_{0}+\mathbf{b}_{1} \mathbf{x}_{1}+\mathbf{b}_{2} \mathbf{x}_{2}+\ldots \ldots . .+\mathbf{b}_{\mathbf{n}} \mathbf{x}_{\mathbf{n}}+\mathbf{e}$

Where, $\mathrm{y}=$ estimated dependent variable (BBVC)

$\mathrm{e}=$ constant (which includes the error term),

$\mathrm{b}=$ regression coefficients and

$\mathrm{x}=$ each independent variable (the individual indicators (predictors) of the component)

$\mathrm{n}=$ number of indicators under a component.

A standard multiple linear regression, called 'the Enter' method, was used for the SPSS analysis. In this method, the user enters all independent variables (the four indicators of the IT manager's role) simultaneously into the model. Variables were evaluated by what they add to the prediction of the dependent variable, which is different from the predictability afforded by the other predictors in the model (Nach, 2009) .

In order to test the component level hypotheses in terms of whether there is a significant linear relationship between the individual components in the theoretical model and the dependent variables, the F-test was used. It involved testing whether the set of the independent variables (indicators) collectively predicts the dependent variable for that particular component. The 'R-squared' multiple correlation coefficients of determination were also reported and used to determine how much variance in the dependent variable can be accounted for by the set of the independent variables. The t-test was used to determine the significance of each of the indicators and beta coefficients were used to determine the magnitude of prediction for each indicator variable. For significant predictors, every one-unit increase in the predictor, meant the dependent variable will increase or decrease the number of unstandardized beta coefficients (Statistics Solutions, 2013)

This section presents the analysis of the relationship between motivation and capability of an IT manager in SME architectural firms and the BBVC. Table 4 lists the variables of the IT manager components.

\section{Hypotheses}

$\mathrm{H}_{1}$ : The motivation and capabilities of IT managers toward innovation in SME architectural firms has a significant correlation with BBVC.

$\mathrm{H}_{0}$ : The motivation and capabilities of IT managers toward innovation in SME architectural firms has no significant correlation with BBVC.

\section{Sub-Hypotheses}

1. Ha: Firms that develop their innovation HC from IT managers with a flexible work life balance are likely to succeed in BBVC.

2. Hb: Firms that develop their innovation HC from IT managers with higher education qualifications are likely to succeed in BBVC.

3. Hc: Firms that develop their innovation HC from IT managers with previous experience are likely to succeed in BBVC.

4. Hd: Firms that develop their innovation HC from IT managers with higher job satisfaction are likely to succeed in BBVC.

Table 1: Variables of the IT manager component

\begin{tabular}{|c|c|c|c|}
\hline \multicolumn{3}{|c|}{ INDEPENDENT VARIABLES } & $\begin{array}{l}\text { DEPENDENT } \\
\text { VARIABLES }\end{array}$ \\
\hline Component & \multicolumn{2}{|c|}{ The motivation and capability of IT manager } & \multirow{5}{*}{$\begin{array}{l}\text { BIM Business Value } \\
\text { Creation (BBVC) }\end{array}$} \\
\hline \multirow{4}{*}{$\begin{array}{l}\text { Indicators } \\
\text { Level }\end{array}$} & 1 & The IT managers has flexible work life balance & \\
\hline & 2 & The IT managers has higher education qualification & \\
\hline & 3 & The IT manager previous IT experience. & \\
\hline & 4 & The IT managers has higher job satisfaction & \\
\hline
\end{tabular}




\section{The Regression Analysis}

A multiple regression analysis is conducted to investigate whether the motivation and capabilities of IT managers toward innovation in SME architectural firms have a significant correlation with BBVC. This involves analysing the effect of four indicators of the IT manager in predicting the BBVC. The preliminary analysis shows that all assumptions are valid and the potential variables of the indicators are accepted to carry out the multiple regression analysis.

Table 2:-Model summary for the IT manager component

\begin{tabular}{|l|l|l|l|l|}
\hline Model & R & R Square & Adjusted R Square & Std. Error of the Estimate \\
\hline 1 & $.723^{\mathrm{a}}$ & .523 & .515 & .99177 \\
\hline $\mathrm{a}$
\end{tabular}

a. Predictors: (Constant), The IT managers have higher job satisfaction; The IT managers have higher education qualifications, The IT managers have previous IT experience. The IT managers have a flexible work life balance

Table 2 shows the multiple linear regression model summary and overall fit statistics. The table shows that the adjusted $\mathrm{R}^{2}$ of the model is 0.515 with the $\mathrm{R}^{2}=0.523$, which means that the linear regression explains $52.3 \%$ of the variance in the data.

Table 3:-Anova test for the IT manager component

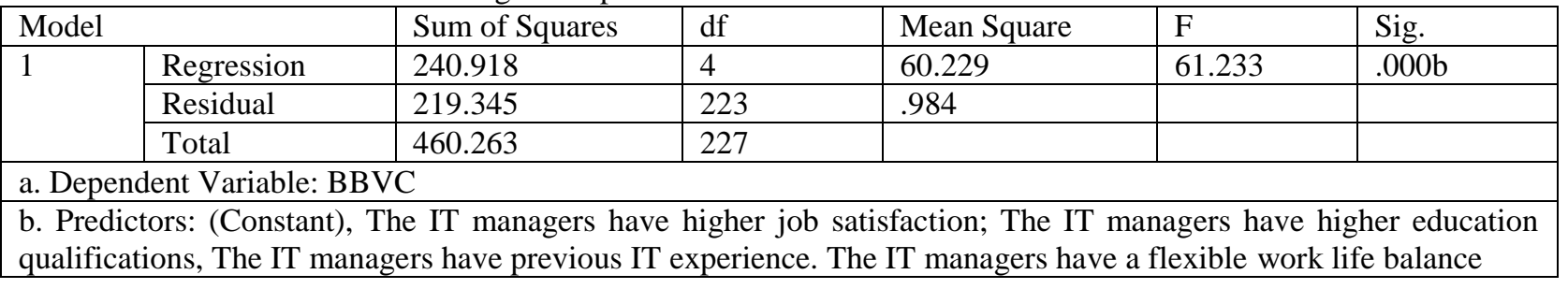

Table 3 shows the linear regression's F-test which has the null hypothesis, $\mathrm{H} 1_{0}$ that there is no linear relationship between the dependent variable and independent variable at the component level (in other words $\mathrm{R}^{2}=0$ ). The F-test show $\mathrm{F}$ value of 61.233 with highly significant $\mathrm{P}$-value; thus, the study can assume that the null hypothesis $\mathrm{H} 3_{0}$ is rejected; Hence, $\mathrm{H}_{1}$ is accepted, which means that, at the components level, there is a significant linear relationship between the motivation and capability of the IT manager and the BBVC in an SME architectural. However, to determine the direct effect, it is essential to conduct further analysis at the indicator level. Hence, the result of the analysis on the level of the indicator is presented in Table 4.

Table 4:-Coefficient showing the linear regression estimates of all the indicators of the IT manager components on BBVC

\begin{tabular}{|c|c|c|c|c|c|c|}
\hline \multirow{2}{*}{\multicolumn{2}{|c|}{ Model }} & \multicolumn{2}{|c|}{$\begin{array}{l}\text { Unstandardised } \\
\text { Coefficients }\end{array}$} & \multirow{2}{*}{$\begin{array}{l}\text { Standardised } \\
\text { Coefficients } \\
\text { Beta }\end{array}$} & \multirow[t]{2}{*}{$\mathrm{t}$} & \multirow[t]{2}{*}{ Sig. } \\
\hline & & $\mathrm{B}$ & Std. Error & & & \\
\hline \multirow[t]{5}{*}{1} & (Constant) & .835 & .168 & & 4.976 & .000 \\
\hline & $\begin{array}{l}\text { The IT managers have a flexible work } \\
\text { life balance }\end{array}$ & .285 & .094 & .307 & 3.042 & .003 \\
\hline & $\begin{array}{l}\text { The IT managers have higher } \\
\text { education qualifications }\end{array}$ & .425 & .092 & .448 & 4.612 & .000 \\
\hline & $\begin{array}{l}\text { The IT managers have previous IT } \\
\text { experience. }\end{array}$ & .178 & .090 & .179 & 1.988 & .048 \\
\hline & $\begin{array}{l}\text { The IT managers have higher job } \\
\text { satisfaction }\end{array}$ & .432 & .080 & .433 & 5.366 & .000 \\
\hline
\end{tabular}

Table 4 shows the linear regression estimates of all the indicators of the IT manager components on BBVC shows the multiple linear regression estimates of all the indicators, thus testing the four Sub-Hypotheses, H1a-H1d, including the intercept and the significance levels, on the effect of each indicator on the IC of BBVC. The unstandardised coefficients' Beta (B) value indicates the extent of the effects for each of the independent variable on the dependent variable BBVC. Table 4 shows there is a significant positive effect on BBVC when firms rely on the 
motivation and capability of an IT manager regarding a higher educational qualification, previous IT experience, higher job satisfaction and a flexible work life balance.

\section{Conclusion:-}

The development of the HC of SME architectural firms in the AEC industry is essential to the business process of BIM adoption; it also helps firms to evaluate their capability for innovation. The development of this capital involved the motivation and capability of all the human resource of the firm from the the IT manager in creating BBVC. For example, while the IT manager's education and experiences add major value in the operational aspect of the BIM, there is a need for the firm to consider their job satisfaction, particularly concerning their work-life balance, which is believed to acknowledge and respond to the IT manager's working and personal needs and thus support their performance of their duties. Nevertheless, the IT manager needs to ensure the continued understanding of the strategic need for planning in the BIM environment and encourage innovativeness and teamwork in settings and to implement strategic plans. Furthermore, education and training are identified as important elements of BIM implementation due to the process and technological changes they bring to an organisation. Hence, there is a need for regular training of the IT manager on the necessity of innovativeness as well as on the way BIM changes the processes of a firm. However, this should be done sensitively rather than as a directive as the need for positive selfmotivation is critical for the success of the firm.

\section{References:-}

1. Aranda-Mena, G., Crawford, J., Chevez, A., \& Froese, T. (2009). Building information modelling demystified: does it make business sense to adopt BIM? International Journal of managing projects in business, 2(3), 419434.

2. Baldwin, J. R., \& Johnson, J. (1996). Business strategies in more- and less-innovative firms in Canada. Research Policy, 25(5), 785-804. doi:10.1016/0048-7333(95)00875-6

3. Barlish, K., \& Sullivan, K. (2012). How to measure the benefits of BIM-A case study approach. Automation in construction, 24, 149-159.

4. Becker, G. S. (1994). Human capital revisited Human Capital: A Theoretical and Empirical Analysis with Special Reference to Education (3rd Edition) (pp. 15-28): The University of Chicago Press.

5. Bew, M., \& Richards, M. (2008). BIM maturity model. Paper presented at the Construct IT Autumn 2008 Members' Meeting. Brighton, UK.

6. Binder, M., \& Coad, A. (2013). Life satisfaction and self-employment: a matching approach. Small Business Economics, 40(4), 1009-1033.

7. McGrawHill Construction (2014). The Business Value of BIM For Construction in Major Global Markets: how contractors around the world are driving innovation with building information modeling. Smart MarketReport McGraw Hill Construction, New York.

8. Curley, M. G. (2004). Managing Information Technology for Business Value: Practical Strategies for IT and Business Managers (IT Best Practices series): Intel Press.

9. Hayton, J. C. (2005). Competing in the new economy: the effect of intellectual capital on corporate entrepreneurship in high-technology new ventures. R and D Management, 35(2), 137-155. doi:10.1111/j.14679310.2005.00379.x

10. Holzer, D. (2015). The BIM Manager's Handbook, Part 2: Change Management: John Wiley \& Sons.

11. Kohli, R., \& Grover, V. (2008). Business value of IT: An essay on expanding research directions to keep up with the times. Journal of the association for information systems, 9(1), 23.

12. Kori, S. i., \& Kiviniemi, A. (2015). TOWARD ADOPTION OF BIM IN THE NIGERIAN AEC INDUSTRY; CONTEXT FRAMING, DATA COLLECTING AND PARADIGM FOR INTERPRETATION (pp. 34-41): http://bimforum.org/wp-content/uploads/2015/05/BIMAS2015Proceedings.compressed.pdf.

13. Lu, S. L., \& Sexton, M. (2009). Innovation in Small Professional Practices in the Built Environment: Wiley.

14. Malhotra, N., Smets, M., \& Morris, T. (2016). Career Pathing and Innovation in Professional Service Firms. The Academy of Management Perspectives, 30(4), 369-383.

15. McGraw-Hill. (2009). The Business Value Of BIM. Getting Building Information Modeling to the Bottom Line. Bedford: McGraw Hill Construction.

16. McGuirk, H., Lenihan, H., \& Hart, M. (2015). Measuring the impact of innovative human capital on small firms' propensity to innovate. Research Policy, 44(4), 965-976. 
17. Morris, S. S., \& Snell, S. A. (2011). Intellectual capital configurations and organizational capability: An empirical examination of human resource subunits in the multinational enterprise. Journal of International Business Studies, 42(6), 805-827. doi:10.1057/jibs.2011.14

18. Nach, E. J. (2009). Instructional use of research-based practices for students with autism spectrum disorder: ProQuest.

19. Racheva, Z., Daneva, M., \& Sikkel, K. (2009). Value creation by agile projects: Methodology or mystery? Paper presented at the International Conference on Product-Focused Software Process Improvement.

20. Romer, P. M. (1990). Human capital and growth: theory and evidence. Paper presented at the CarnegieRochester conference series on public policy.

21. Shipton, H., Fay, D., West, M., Patterson, M., \& Birdi, K. (2005). Managing People to Promote Innovation. Creativity and Innovation Management, 14(2), 118-128. doi:10.1111/j.1467-8691.2005.00332.x

22. Sinclair, D. (2012). BIM overlay to the RIBA outline plan of work. London, UK: RIBA.

23. Solutions, S. (2013). Data analysis plan: Moderation Analysis [WWW Document]: Retrieved.

24. Succar, B. (2009). Building information modelling maturity matrix. Handbook of Research on Building Information Modeling and Construction Informatics: Concepts and Technologies, IGI Global, 65-103.

25. Succar, B., \& Kassem, M. (2015). Macro-BIM adoption: Conceptual structures. Automation in Construction, 57, 64-79.

26. Succar, B., Sher, W., \& Williams, A. (2012). Measuring BIM performance: Five metrics. Architectural Engineering and Design Management, 8(2), 120-142.

27. Toner, P. (2011). Workforce skills and innovation: an overview of major themes in the literature. OECD Education Working Papers(55), 0_1.

28. Vass, S. (2014). A proposed BIM business value model. Paper presented at the 30th Annual Association of Researchers in Construction Management Conference, ARCOM 2014; Portsmouth; United Kingdom.

29. Vass, S. (2015). An Organizational Perspective on the Business Value of BIM. KTH Royal Institute of Technology.

30. Yang, C.-C., \& Lin, C. Y.-Y. (2009). Does intellectual capital mediate the relationship between HRM and organizational performance? Perspective of a healthcare industry in Taiwan. The International Journal of Human Resource Management, 20(9), 1965-1984.

31. Zhou, J., \& George, J. M. (2001). When job dissatisfaction leads to creativity: Encouraging the expression of voice. Academy of Management journal, 44(4), 682-696. 